\title{
Politicas de Visualidade, Práticas Visuais e a Construção de Espaços de IMAGINAÇÃo
}

\author{
Sandra C. S. Marques e Ricardo Campos \\ CRIA/CICS.Nova, Lisboa, Portugal
}

\section{INTRODUÇÃo}

A visualidade é, apesar de tantas vezes ignorada por parte dos cientistas sociais, uma dimensão fundamental da nossa vida e da forma como nos relacionamos com o mundo e com os outros. Quando falamos de visualidade não estamos a remeter para a capacidade fisiológica humana de percepcionar o mundo visualmente, mas antes para o facto da relação visual que estabelecemos com o mundo ser social e culturalmente construída, assente não apenas em códigos e linguagens aprendidos, mas também num conjunto de objectos, tecnologias e processos de mediação (Berger 1999, Sicard 2006). Logo, a visualidade remete não apenas para as questões da percepção, mas também para a interpretação e significação.

Interessa-nos, acima de tudo, destacar a visualidade enquanto processo social. $\mathrm{Na}$ verdade, podemos falar de um conjunto de processos sociais que operam no terreno da visualidade. Porém, aquilo que gostaríamos de frisar é que este é, acima de tudo, um terreno de troca e de comunicação entre pessoas. Abordar a visualidade na perspectiva da comunicação implica que tenhamos em consideração duas dimensões, profundamente interligadas. Assim, se por um lado, a visualidade remete para a capacidade que temos de aceder visualmente àquilo que nos rodeia, por outro, endereça-nos para as competências criativas através das quais produzimos visualmente a realidade, através de uma variedade de linguagens, artefactos, etc. Ou seja, não apenas exploramos visualmente o mundo, como também criamos visualmente o mundo. Esta é uma questão de fulcral importância se queremos discutir o papel da visualidade, da imagem ou da cultura visual no mundo contemporâneo, pois não apenas nos coloca no papel "passivo" de quem olha, contempla e recebe informação visual, mas nos relembra da nossa capacidade inventiva, da nossa agência e poder de intervenção no mundo.

Em nosso entender a agência criativa reside na capacidade de produção de bens que se destinam, de alguma forma, a comunicar algo em termos visuais. Esta agência não se reflecte apenas na produção de imagens, mas também na fabricação de uma série de artefactos e no uso 
de recursos que compõem a nossa esfera de representação visual. Assim, a forma como empregamos o corpo ou o vestuário constituem elementos de comunicação visual. Expressamo-nos através da linguagem do corpo, das suas posturas e performatividade, mas também através dos diferentes significados que se alojam nas tatuagens, piercings, ornamentos e peças de vestuário. Numa sociedade altamente consumista como a nossa, acrescentaríamos o consumo de bens como elemento constitutivo de certos estilos de vida, com uma forte componente visual (Ewen 1988, Featherstone 1991). Neste domínio também há agência e criatividade, pois há opções e formas de "bricolage" que não são meramente utilitárias, mas também simbólicas e que pretendem comunicar algo sobre quem somos e como vivemos.

Estes casos que referimos dizem respeito à esfera do individuo e da sua agência. Porém a visualidade abrange, igualmente, entidades colectivas e instituições sociais. O Estado, a igreja ou as grandes empresas também agem neste campo. Seja na arquitectura monumental que ostenta o seu poder e o seu domínio sobre o espaço, seja na monopolização ou domínio de certos canais de produção e difusão de imagens, seja na imposição de uma certa mundividência, seja pelo aperfeiçoamento dos mecanismos de vigilância, entre muitas outras situações. O poder (político, religioso, económico) sempre teve necessidade de agir sobre o visível, tendo perfeita consciência que esta é uma arena fulcral de manutenção ou disputa de poder (Balandier 1999, Jay e Ramaswamy 2014, Pinney 2003, Robins 1996, Werbner et al. 2014).

A visualidade não se resume às imagens, como ficou explicito nas nossas palavras. No entanto, não há como ignorar o facto destas desempenharem um papel de central relevância no mundo actual. As imagens há muito que fazem parte do nosso quotidiano. $\mathrm{O}$ formato retangular converteu-se no enquadramento dominante através do qual acedemos às imagens engendradas pelo homem, indicando-nos que estas têm vida própria no interior de certas fronteiras, de certas molduras. Pintura, desenho, fotografia, cinema ou televisão. Cada vez mais as imagens digitais e os seus ecrãs. A televisão ficou conhecida como uma "janela para o mundo", por nos fornecer acesso a um conjunto de representações visuais sobre realidades distantes. Por vezes esquecemos que a televisão, tal como muitos dos media (áudio)visuais que conhecemos são mediadores de sentido, constroem imagens acerca da realidade. $\mathrm{O}$ mesmo princípio se pode aplicar a outros circuitos de produção, circulação e consumo de imagens, estejam estes ao serviço do Estado, das indústrias culturais ou de actores menos poderosos (Banks 2005).

Daí que, para além da dimensão puramente estética, não poderemos ignorar a dimensão política presente nos processos de comunicação visual e de produção de imagens. A dimensão política está, desde logo, presente no facto de considerarmos que a imagem tem poder, é uma "arma" determinante para influenciar pessoas. Mais relevante se torna esta questão no caso particular dos circuitos de difusão de imagens em massa, com capacidade para alcançar um número elevado de pessoas (Thompson 1998). Deste ponto de vista o cinema e a televisão vieram inaugurar uma nova época. Mais recentemente os media digitais, pela sua irradiação e carácter democratizador, trouxeram-nos outras questões. Actualmente o poder de intervenção na esfera pública não é exclusivo daqueles que detêm capacidade económica e técnica para produzir imagens em termos profissionais. Cada vez mais há circuitos extra-institucionais, minoritários e amadores que desafiam a hegemonia de alguns. As tecnologias digitais de produção de imagem tornaram-se bastante acessíveis, o crescimento explosivo da rede de internet e das tecnologias móveis, bem como a multiplicação de softwares e plataformas digitais de comunicação tornaram bem mais complexo o panorama da comunicação (áudio)visual (Miller et al. 2016). Plataformas 
como o Facebook, o Instagram , o Youtube, entre outras converteram-se em lugares de encontro, diálogo e comunicação que podem operar fora dos circuitos dominantes (Loader 2007).

A política da imagem e da visualidade na contemporaneidade está, então, directamente associada a esta articulação entre poder e mediação. As imagens que dominam o nosso quotidiano são, cada vez mais, o resultado de processos de mediação tecnológica em que operam diferentes instâncias. Daí que o poder se expresse através dos mediascapes (Appadurai 2004), através da capacidade para controlar ou dominar os aparatos tecnológicos (de produção, circulação, consumo, etc.). É sabido o papel que as indústrias culturais, de Hollywood a Bollywood, têm na disseminação de certos imaginários e narrativas imagéticas. O mesmo se aplica aos consórcios mediáticos, cuja acção é determinante na imposição de certas verdades e naturalização de determinada mundivisão. Sabemos, também, que o poder e a abrangência da acção destas entidades é variável, apesar de haver circuitos e narrativas que se tendem a impor como claramente hegemónicos.

Chegamos por isso à conclusão que uma imagem nunca é “apenas” uma imagem. Há muito que se desmontou a aparente transparência e objectividade da imagem técnica (Joly 2003). Reconhecer o poder das imagens e das suas tecnologias é admitir que estas são recursos potencialmente ao serviço de diferentes actores sociais. Os mais poderosos, o Estado ou as grandes empresas utilizam-nas na propaganda ou na publicidade, criando as suas próprias narrativas que tendem a servir os seus interesses e uma certa mundividência. As indústrias culturais estimulam a lógica do espectador-consumidor, ávido de certos imaginários arquitectados pelo cinema, televisão ou videojogos. Curiosamente estes são sectores que aparentemente caminham numa certa confluência técnica e narrativa, quando verificamos que certos heróis, ícones mediáticos e demais construções da sociedade do espectáculo, transitam entre os noticiários televisivos, os filmes de ficção e os videojogos, tornando mais ténue as fronteiras entre realidade e ficção, espectáculo e documental, entretenimento e informação (Jenkins 2006). Vivemos, por isso, no meio de permanentes simulacros e simulaçôes (Baudrillard 1991).

Ao questionarmos sobre como podem construir-se modos alternativos de ver e de saber, somos portanto remetidos a interpelar os mecanismos dominantes que operam na produção e consumo de imagens na chamada indústria cultural e os seus efeitos de regressão da capacidade de reflexão crítica e da tolerância à imprevisibilidade. A relação directa entre processos ideológicos, mudanças tecnológicas e transformação estrutural dos modos de produção que opera no desenvolvimento da sociedade contemporânea mercantilizada é a mesma que subjaz à crescente massificação de imagens (áudio)visuais e sua comodificação em valores esquemáticos da realidade. Ou seja, a última é uma extensão ou parte da indústria e não consequência ou efeito. Mas por mais totalitária que seja a tendência da indústria cultural e do seu potencial de anulação dos mecanismos de reflexão e crítica, ela não se apresenta sem contradições e fendas. Ela admite a dupla função de representar e consolidar a ordem existente e ao mesmo tempo criticá-la e denunciá-la como imperfeita e contraditória.

Em resumo, pensar a política no campo da visualidade é assumir, não apenas processos de dominância, mas também de conflito e negociação. Não podemos descartar a capacidade que o cidadão comum ou certos grupos mais desalinhados têm na produção de narrativas contra-hegemónicas, na construção de espaços e imaginários de resistência. No campo da arte urbana, do activismo digital ou do artivismo, diversos são os exemplos de criação de imagens e narrativas dissidentes, que desvendam e problematizam formas de desigualdade, de exploração, de violência, etc. A visualidade é, por isso, uma arena política de extrema relevância para pensarmos o 
mundo contemporâneo. A luta em torno da imposição de sentido sobre a realidade depende da capacidade dos actores de disputarem as tecnologias e circuitos de circulação de imagens e narrativas visuais. Foi em torno destas questões que o dossiê que aqui apresentamos foi desenhado.

A proposta de realização deste dossiê surge inicialmente como resultado de um painel organizado no âmbito do VI Congresso da Associação Portuguesa de Antropologia ocorrido em 2016 na cidade de Coimbra. O título do painel era precisamente "Políticas de Visualidade, Práticas Visuais e a Construção de Espaços de Imaginação". Este momento de encontro permitiu-nos debater um conjunto de questões, servindo de inspiração para alargar o leque de eventuais intervenções e linhas de exploração. Os contributos que aqui trazemos são muito variados do ponto de vista das temáticas e dizem respeito a contextos empíricos diversos. Em comum trazem à discussão a dimensão política da visualidade, nomeadamente a capacidade que o cidadão comum, individualmente ou em grupo, tem para intervir na esfera pública recorrendo à fotografia, ao graffiti, ao vídeo, etc. A seleção acolhe autores de áreas diversas abraçando contribuições a partir da Antropologia, Artes Visuais, Belas Artes, Comunicação e Estética. Propomos uma reflexão multifocal e com pontos de partida diversos sobre políticas de visualidade, percorrendo explorações analíticas de práticas visuais (e audiovisuais) que procuram criar espaços de repúdio, contestação e imaginação alternativos. Como antecipável, pelo seu potencial revolucionário, a arte e as práticas de activismo com recurso à imagem, assumem grande destaque.

O ensaio de António Contador inicia este dossiê abordando precisamente algumas das questões envolvidas no processo de codificação-descodificação de imagens artísticas problematizando a noção de espera no contexto da experiência artística e das possíveis relações autor-espectador. A partir da fenomenologia da espera neste contexto, fornece pistas para a reflexão sobre a criação de contextos de produção e recepção de imagens e para a dupla erudição exigida de saber-cifrar do autor e saber-decifrar do espectador se algum tipo de transformação for almejado. Enquanto espectador, diz-nos o autor, a postura da espera pode ser a de esperante, acolhendo como quem aceita uma dádiva sem o dever de a retribuir, e contentando-se o autor com a imobilidade e a contemplação, sem ambicionar algo que faça querer ir ou ver além ou, por outro lado, antecipante ou expectador, impondo ao autor o "disparo" estético e político que incentivará o espectador a posicionar-se, também ele, num campo extra-estético através da arte.

O artigo de Susana Rocha transporta-nos para o universo de três artistas contemporâneos latino americanos, selecionados como exemplares da capacidade interventiva da arte junto da sociedade: Berna Reale (Brasil), Teresa Margolles (México) e Oscar Muñoz (Colômbia). Através da análise de algumas das suas obras, identifica como característica unificadora destes três dispares artistas, um sentido activismo social na denúncia sistemática da violência do comportamento humano, designadamente através da contestação do silêncio e do esquecimento. Argumenta a investigadora que, embora o posicionamento face ao uso da arte como modo de luta social não seja específico ou transversal aos artistas oriundos da América Latina, essa postura parece vincar-se com maior firmeza ali do que na maioria dos artistas oriundos do contexto europeu e norte-americano.

Os dois artigos seguintes, suportados em pesquisas etnográficas, trazem-nos exemplos de experiências de artivismo ou activismo com recurso à imagem, explorando alcances e limitações dos modos como estas práticas interpelam criticamente lógicas hegemónicas de poder e desigualdades de representação. Guilhermo Aderaldo reúne três exemplos de associativismo, o 
“Coletivo Vídeo Popular", "Projetação" e "Imargem”, tomando como eixo central de análise a forma como têm usado novas ferramentas tecnológicas e recursos visuais como meio de consolidar táticas de mobilização e envolvimento nos espaços públicos urbanos. Ao apostarem em intervenções que nos levam a refletir sobre a dimensão relacional dos territórios, estas novas formas de agência não apenas usam a cidade como cenário para as suas práticas artísticas, mas também se valem delas para abrir espaço à reinvenção da percepção e interpretação do que é "cidade". Fabiene Gama, por sua vez, dá-nos a conhecer o projecto "Imagens do Povo" que promove a formação de documentaristas fotográficos entre moradores de favelas cariocas com o objetivo de produzir novas representações dessas áreas e dos seus habitantes. Descreve como um destes fotógrafos terá documentado o cadáver de uma criança de oito anos assassinada pela polícia, em 2008. A divulgação dessas imagens em diferentes meios de comunicação terá desencadeado uma série de eventos, exigindo que o grupo refletisse sobre o alcance, necessidades e repercussões das suas práticas, redefinindo os limites das suas actividades de documentação. Através do acompanhamento deste caso, a antropóloga explora os limites da autorrepresentação fotográfica de moradores de favelas no Rio de Janeiro e da produção de narrativas que desautorizam versões oficiais.

Sobre a disputa por espaços de significação e representação através da imagem no jogo de relações de força entre o dominante e o marginal, Hely Geraldo Costa Júnior examina o caso dos graffiti do muro do Jockey Club na cidade Rio de Janeiro e Samuel Leal Barquete toma como material de análise imagens televisivas de índios Xavante na década de 1980, momento histórico em que o movimento indígena organizado passou por profundas transformações no Brasil. Sob perspectivas de análise distintas, ambos os textos reflectem sobre as dificuldades e armadilhas dos processos de busca por reconhecimento das expressões minoritárias. No primeiro caso, a passagem do muro transgressor ao muro controlado é vista como modelar do modo como o graffiti passou a ser definido pelo poder económico. O local onde está inserido, sua estética, sua temática e, principalmente, os nomes dos grafiteiros que se destacam são determinados pelo capital. $\mathrm{Na}$ busca por reconhecimento e valor de troca, conclui o autor, muitos grafiteiros se desterritorializam da transgressão e da marginalidade para reterritorializarem espaços docilizados, legalizados e comercialmente valorizados. No segundo caso, os eventos explorados envolvem a dimensão complexa do contacto interétnico. A busca por reconhecimento e visibilidade exige das populações marginais a modulação de narrativas sobre si a partir do idioma do outro dominante. O texto aborda os processos de instrumentalização das autorrepresentações de índios Xavante e da sua relação com os meios de comunicação massificada, evidenciando as tensões e armadilhas políticas que caracterizaram o movimento geral a que o autor chama de “entrada nas imagens" realizado pelos Xavante na segunda metade do século XX.

O ensaio visual "Rousselfie project" encerra o dossiê. O autor Fábio Gatti combina aqui uma amostra da sua narrativa fotográfica com uma entrevista sobre o projecto maior em que se enquadra. Este artificio literário permite-lhe adoptar um formato de carácter reflexivo revelando, a propósito dos seus resultados, os pressupostos e as metodologias utilizadas, as razões das suas escolhas e a sua relação com este projecto artístico manifestamente político.

Dados os constrangimentos inerentes aos formatos de edição, não nos foi possível acolher outros dos muitos artigos e ensaios visuais que nos foram propostos e que aqui teriam lugar. A todos agradecemos pela forma como responderam ao nosso desafio de contribuir para a divulgação da importância da visualidade enquanto arena política relevante para pensarmos o mundo contemporâneo. Nas últimas duas décadas, tem sido crescente a inquietação com questões da 
cultura visual e das múltiplas dimensões da visualidade, sobretudo no que diz respeito à sua importância na constituição de identidades e subjetividades. Procurámos centrar-nos, aqui, na relevância da sua dimensão política enquanto elemento operante de mudança e transformação. Em contextos diversificados, somos surpreendidos por visualidades e práticas visuais que ganham espaço construindo ambientes e territórios visuais alternativos. Ainda que marginais ou sob conflito, solicitam-nos rupturas simbólicas e contravenções epistemológicas que impelem à reinvenção das nossas práticas de ver e de pensar. Parafraseando Theodor Adorno, o potencial contido nas imagens não nos deve cegar para o modo como funcionam na atualidade mas as suas possibilidades utópicas e emancipatórias inerentes às forças tecnológicas são também capazes de desmantelar os monopólios da cultura (Adorno e Horkheimer 1985).

\section{RefERÊnCIAS Bibliográficas}

Adorno, Theodor e Horkheimer, Max. 1985. Dialética do esclarecimento. Rio de Janeiro: Zahar. Appadurai, Arjun. 2004. Dimensões culturais da globalização. A modernidade sem peias. Lisboa: Teorema.

Balandier, Georges. 1999. O poder em cena. Coimbra: Minerva.

Banks, Marcus. 2005. Visual methods in social research. London, Thousand Oaks, New Delhi: Sage.

Baudrillard, Jean. 1991. Simulacros e simulação. Lisboa: Relógio d’Água.

Berger, John. 1999. Modos de ver. Lisboa: Edições 70.

Ewen, Stuart. 1988. All consuming images. The politics of style in contemporary culture. New York: Basic Books.

Featherstone, Mike. 1991. Consumer culture and postmodernism. London, Newbury Park, New Delhi: Sage Publications.

Jay, Martin e Ramaswamy, Sumathi eds. 2014. Empires of vision. A reader. Durham: Duke University Press.

Jenkins, Henri. 2006. Convergence culture: where old and new media colide. New York and London: New York University Press

Joly, Martine. 2003. A imagem e sua interpretação. Lisboa: Edições 70.

Loader, Bryan D. ed. 2007. Young Citizens in Digital Age: political engagement, young people and new media. London and New York: Routledge.

Miller, Daniel et al. 2016. How the world changed social media. London: UCL Press.

Pinney, Christopher. 2003. "Photos of the gods". The printed image and political struggle in India. London: Reaktion.

Robins, Kevin. 1996. Into the image. London and New York: Routledge.

Sicard,M. 2006. A fábrica do olhar. Imagens de Ciência e aparelhos de visão (Século XV-XX), Lisboa: Edições 70.

Thompson, John. 1998. Ideologia e cultura moderna - teoria social critica na era dos meios de comunicação de massa. Petrópolis: Editora Vozes.

Werbner, Pnina et al. eds. 2014. The political aesthetics of global protest. The Arab Spring and beyond. Edinburgh: Edinburgh University Press. 